\title{
Multi-Laser Powder Bed Fusion Benchmarking—Initial Trials with Inconel 625
}

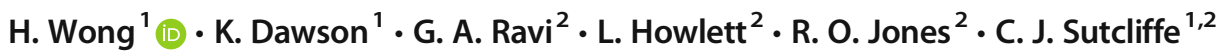

Received: 3 June 2019 / Accepted: 12 September 2019 / Published online: 9 November 2019

(C) The Author(s) 2019

\begin{abstract}
Production rate is an increasingly important factor in the deployment of metal additive manufacturing (AM) throughout industry. To address the perceived low production rate of metal AM systems based on single-laser powder bed fusion (L-PBF), several companies now offer systems in which melting has been parallelised by the introduction of multiple, independently controlled laser beams. Nevertheless, a full set of studies is yet to be conducted to benchmark the efficiency of multi-laser systems and, at the same time, to verify if the mechanical properties of components are compromised due to the increase in build rate. This study addresses the described technology gaps and presents a 4-beam L-PBF system operating in "single multi" (SM) mode (SM-L$\mathrm{PBF}$ ) where each of the four lasers is controlled so that it melts all of a particular components' layers and produces specimens for comparison with standard L-PBF specimens from the same machine. That is all four lasers making all of some of the parts were compared to a single-laser manufacturing all of the parts. Build parameters were kept constant throughout the manufacturing process and the material used was Inconel 625 (IN625). Stress-relieving heat treatment was conducted on As-built (AB) specimens. Both $\mathrm{AB}$ and heat-treated (HT) specimen sets were tested for density, microstructure, tensile strength and hardness. Results indicate that the stress-relieving heat treatment increases specimen ductility without compromising other mechanical properties. SM-L-PBF has achieved a build rate of $14 \mathrm{~cm}^{3} / \mathrm{h}$ when four $200 \mathrm{~W}$ lasers were used to process IN625 at a layer thickness of $30 \mu \mathrm{m}$. An increase in the build rate of 2.74 times (build time reduction: 63\%) has been demonstrated when compared to that of L-PBF, with little to no compromises in specimen mechanical properties. The observed tensile properties exceed the American Society for Testing Materials (ASTM) requirements for IN625 (by a margin of 22 to $26 \%$ in the $0.2 \%$ offset yield strength). Average specimen hardness and grain size are in the same order as that reported in literatures. The study has demonstrated that a multi-laser AM system opens up opportunities to tackle the impasse of low build rate in L-PBF in an industrial setting and that at least when operating in single mode there is no detectable degradation in the mechanical and crystallographic characteristics of the components produced.
\end{abstract}

Keywords Additive manufacturing $\cdot$ Multi-laser powder bed fusion $\cdot$ Selective laser melting $\cdot$ Mechanical properties $\cdot$ Inconel 625

\section{Introduction}

Advances in material discovery and efficient manufacturing are essential to the continued adoption of any new

H. Wong

hay.wong@liv.ac.uk

K. Dawson

kdaws@liverpool.ac.uk

G. A. Ravi

Ravi.Aswathanarayanaswamy@Renishaw.com

L. Howlett

Laura.Howlett@Renishaw.com manufacturing technology. In order to secure the future of new innovations, methods which enable speedy material development, with minimum waste and post-processing combined with a reduced cost must be developed. Against this

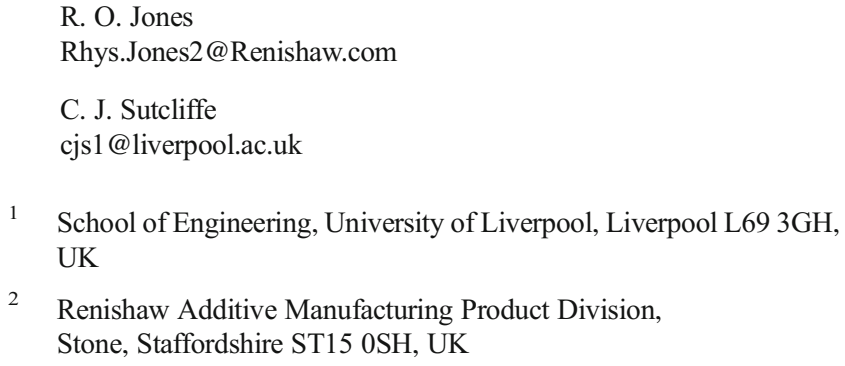

2 Renishaw Additive Manufacturing Product Division, Stone, Staffordshire ST15 0SH, UK 
backdrop, additive manufacturing (AM) has been identified as a disruptive manufacturing technique for the production of net-shape metallic components [1]. Whilst traditional manufacturing methods, such as machining and casting, will remain important, AM offers many advantages in terms of design freedom and material economy. Selective laser melting (SLM) or laser powder bed fusion (L-PBF) is one of the metal AM techniques beginning to achieve production uptake. LPBF is a metallic powder bed, laser-driven, layer-by-layer process which utilises a scanning galvanometer system to divert a process laser across a metallic powder bed in order to create complex 3D components [2]. Despite the perceived benefit of L-PBF, there is, however, an impasse due to the low build rate [3] owing to the scanning mirror inertia in the galvanometer [2]. Electron beam melting (EBM) is another metal AM technique [4] posing a threat to the continued adoption of commercial L-PBF. This technology has a major advantage in scan speed due to the utilisation of massless electromagnetic lenses to manipulate a material-processing electron beam [4]. This enables the EBM process to have a build rate in the region of $80 \mathrm{~cm}^{3} / \mathrm{h}$ [1], which is currently beyond the reach of any L-PBF system (single $200 \mathrm{~W}$ laser SLM typical build rate, $5 \mathrm{~cm}^{3} / \mathrm{h}[1]$ ).

Multi-laser processing has been reported before, for example, by Andani et al [5] when the team investigated spatter formation, and by Li et al [6] when his group studied the microstructure and mechanical properties of Ti-6Al-4V components fabricated by multi-laser melting. However, experiments are yet to be carried out to quantify the effectiveness of multi-laser systems and, at the same time, to investigate if the mechanical properties of specimens are compromised due to the increase in build rate. This study aims to address the described research gaps and present a study involving a multilaser L-PBF system for the processing of Inconel 625 (IN625). The system is designed to improve the speed and build efficiency of L-PBF systems to compete with the production speed of EBM whilst maintaining the mechanical and microstructural properties of components. The multi-laser system offers numerous advantages over the current crop of available L-PBF systems. If multi-laser L-PBF is to be an industrially acceptable process capable of the manufacture of regulated components, then effects caused by the use of multiple laser sources on component mechanical properties must be understood. This paper investigates the effect of using multiple laser beams for L-PBF. A 4-beam system was used to produce specimens from IN625 powder with a layer thickness of 30 $\mu \mathrm{m}$. Stress-relieving heat treatment was conducted to relieve thermal residual stress on as-built $(\mathrm{AB})$ specimens. Both $\mathrm{AB}$ and heat-treated (HT) specimen sets were tested for density, hardness, tensile strength and microstructure. Single-laser specimen test results were compared to multi-laser results to investigate any influence from the use of multiple laser sources on mechanical properties.

\section{Materials and Methods}

This section describes the materials and methods used in this study in the following order: equipment; L-PBF laser beam arrangements; specimen type; powder properties; process optimisation method; heat treatment; mechanical testing conditions.

\subsection{Manufacturing Equipment}

Specimens were manufactured using a L-PBF and a prototype SM-L-PBF machine. The prototype machine has the same basic configuration as a RenAM500Q (Renishaw, UK). The machine has four individually controlled beam paths with $500 \mathrm{~W}$ modulated laser light at $1070 \mathrm{~nm}$. Galvanometer scanners are provided in each channel with each scanner being inserted into a water-cooled aluminium housing. This housing provides consistent cooling, maximising the pointing stability of each laser channel. The light is delivered through an active (no f-theta) focusing system to the powder bed ensuring consistent $80 \mu \mathrm{m}$ spot size over the $250 \mathrm{~mm} \times 250 \mathrm{~mm}$ build area. A point-based exposure strategy is used with a maximum modulation rate of $25 \mathrm{k} \mathrm{Hz}$ (minimum exposure time is 40 $\mu \mathrm{s})$ with a $10-\mu$ s resolution. Inert gas shielding is provided by vacuum swing inert monitored to an accuracy of $\pm 10 \mathrm{ppm}$. Gas filtering is performed using a dual-filter paper media filter with high gas flow rate being maintained by a large capacity $180 \mathrm{~m}^{3} / \mathrm{h}$ pumping system. Gas temperature is controlled using a water-cooled heat exchanger in the gas stream (intercooler). Positioning control of the laser beam is achieved using a 16bit digital scanning system providing spatial positioning and temporal control. All data to drive the process is produced using QuantAM (Renishaw, UK), a standard AM file production software system which takes STL input producing MTT control files in the usual manner. The MTT control files produced are subsequently handled on the machine by a laser scheduling and control system which splits the MTT file producing data streams to control each channel of the machine. This architecture allows standard commercially available build setup software to drive any number of lasers.

The characteristics described above are essential for the successful implementation of multi-laser L-PBF, and the attainment of these consistent process conditions for the application of multi-laser L-PBF must not be underestimated. The remainder of the machine characteristics are of little consequence in this study and hence the reader is directed to reference [7] should further information be required.

\subsection{Single- and Multi-Laser Selective Melting Arrangement}

Two different L-PBF arrangements were involved in this study. Unlike in the single-laser powder bed fusion (L-PBF) 
setup, the multi-laser configuration has each specimen produced with an individual laser directed to it, this is the socalled single-multi-laser powder bed fusion (SM-L-PBF) mode. Table 1 gives details of the arrangements and Fig. 1 depicts the two different laser paths involved.

\subsection{Specimen Type and Build Configuration}

Two types of specimen were manufactured to investigate the influence of the two laser arrangements, i.e. L-PBF and SML-PBF, on mechanical properties. They are the $10 \mathrm{~mm} \times$ $10 \mathrm{~mm} \times 10 \mathrm{~mm}$ cubes and $\varnothing 14 \mathrm{~mm} \times 100 \mathrm{~mm}$ cylinders, hereafter referred to as cubes and cylinders. Table 2 describes the specimen types and the mechanical testing which they are designed for, whilst Fig. 2 depicts the build configuration of specimens across the L-PBF machine processing area.

\subsection{Feedstock Powder}

The IN625 powder used for both L-PBF and SM-L-PBF is standard gas atomised powder material supplied by Renishaw with characteristics indicated in Table 3.

\subsection{Process Optimisation}

Process optimisation was conducted on In718 and transferred to In625 for this study. The process window was identified by building $10 \mathrm{~mm} \times 10 \mathrm{~mm} \times 10 \mathrm{~mm}$ cubes and evaluating their optical density. Subsequently, a half-factorial design of experiments (DOE) methodology was used to optimise the process window. The DOE was developed in Minitab® 17 (Minitab Inc., USA) over four process variables; power, point distance, exposure time, and hatch distance, in accordance with the Renishaw DOE manual.

\subsection{Heat Treatment}

L-PBF manufactured components suffer from thermal residual stress [9] and annealing was carried out to relieve the stress [10]. AB cubes and cylinders form L-PBF and SM-L-PBF builds were heat-treated in a vacuum furnace at $1048 \pm 10$ ${ }^{\circ} \mathrm{C}$ for $60 \mathrm{~min}$, with a heating rate of $9{ }^{\circ} \mathrm{C} / \mathrm{min}$ under $1 \times$ $10^{-4}$ mbar to $1 \times 10^{-6}$ mbar. The holding time was in accordance with industrial common practice of $1 \mathrm{~h}$ per inch of maximum cross section [11]. HT specimens were then cooled in the furnace to room temperature at 1 bar argon gas pressure.

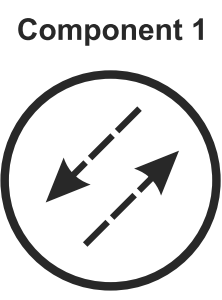

Component 2

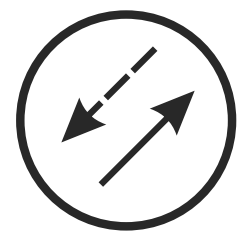

L-PBF

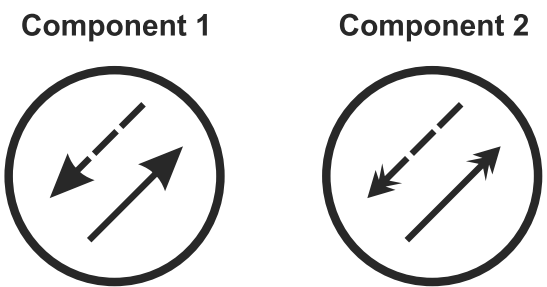

SM-L-PBF

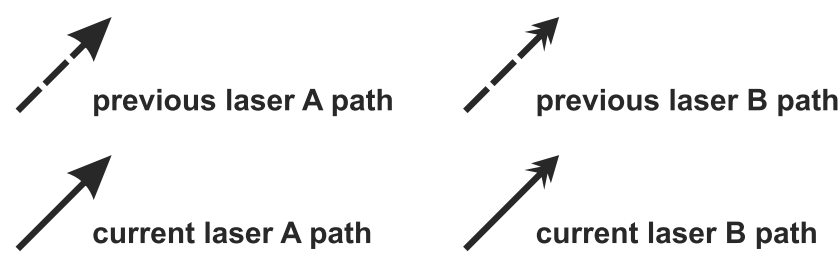

Fig. 1 L-PBF and SM-L-PBF laser paths schematic

\subsection{Automated Polishing}

To facilitate rapid and consistent production of specimens, automated polishing was used. AB and $\mathrm{HT}$ cubes from LBPF and SM-L-PBF were automatically polished using a Buehler Automet ${ }^{\mathrm{TM}} 250$ grinder polisher (Buehler, USA) to $20 \mathrm{~nm}$ surface finish with the use of non-crystallising colloidal silica.

\subsection{Optical Density Testing}

Optical density testing was carried out on $\mathrm{AB}$ and $\mathrm{HT}$ cubes from L-PBF and SM-L-PBF by inspection using a SmartScope ${ }^{\circledR}$ ZIP 300 (OGP, UK) optical CMM. Twenty images of each cube were taken, stitched together, threshold applied to generate binary images, and pixel counted to reveal the metallurgical porosity of the specimens. This method is able to detect pores of $14 \mu \mathrm{m}$ in diameter.
Table 1 The two different L-PBF arrangements involved in this study

\begin{tabular}{llll}
\hline Arrangement & Number of lasers & Laser type(max. power) & Wavelength $(\lambda)$ \\
\hline L-PBF & 1 & $200 \mathrm{~W}$, modulated $(500 \mathrm{~W})$ & $1070 \mathrm{~nm}$ \\
SM-L-PBF & 4 & $200 \mathrm{~W}$, modulated $(500 \mathrm{~W})$ & $1070 \mathrm{~nm}$ \\
\hline
\end{tabular}


Table 2 Specimen type and corresponding mechanical testing

\begin{tabular}{ll}
\hline Specimen type & Mechanical Testing \\
\hline $10 \mathrm{~mm} \times 10 \mathrm{~mm} \times 10 \mathrm{~mm}$ cube & Optical density, Vickers hardness, microstructure \\
$\varnothing 14 \mathrm{~mm} \times 100 \mathrm{~mm}$ cylinder & Tensile \\
\hline
\end{tabular}

\subsection{Microstructure Evaluation}

Electron backscattered diffraction (EBSD) allows the measurement of the crystal orientation and grain size of the specimens. An AB and HT cube from L-PBF and SM-L-PBF were examined in three principle directions, i.e. the $\mathrm{XY}, \mathrm{XZ}$ and $\mathrm{YZ}$ planes, with the $\mathrm{Z}$ direction being the L-PBF build direction. Specimens were prepared with standard metallographic methods, including auto-grinding and auto-polishing. Hot mounting with conductive resin was carried out on the specimens following polishing. EBSD measurements were performed using a Helios 600i NanoLab TM (FEI Company, USA), dual FIB/SEM equipped with a DigiView ${ }^{\mathrm{TM}_{\text {system }}}$ (EDAX, USA) and Orientation Imaging Microscopy (OIM) data collection and analysis software (EDAX, USA). Specimens were tilted to $70^{\circ}$ to the incident beam and measurements were recorded using an acceleration voltage of 20 $\mathrm{kV}, 5.5 \mathrm{nA}$ beam current and step size of $5 \mu \mathrm{m}$.

\subsection{Tensile Testing}

Tensile testing was carried out on $\mathrm{AB}$ and $\mathrm{HT}$ cylinders from L-PBF and SM-L-PBF in accordance with the ASTM standard E8/E8M [12], using an Instron ${ }^{\circledR} 5984$ tensile testing machine (Instron, USA) equipped with a UKAS calibrated $100 \mathrm{kN}$ load cell and an Instron ${ }^{\circledR}$ extensometer (Instron, USA). The $\varnothing 14 \mathrm{~mm} \times 100 \mathrm{~mm}$ cylinders were machined down to $\varnothing 6 \mathrm{~mm} \times 100 \mathrm{~mm}$ and tests were conducted using strain rates of $0.005 \mathrm{~min}^{-1}$ (start to yield point) and $0.05 \mathrm{~min}^{-1}$ (yield point to failure) with the experiments being logged and controlled using the Bluehill@ 3.76 software (Instron, USA).

\subsection{Vickers Hardness Testing}

Vickers hardness testing was carried out on the polished $\mathrm{AB}$ and HT cubes from L-PBF and SM-L-PBF builds in accordance with ASTM standard E92 [13] using a Wilson ${ }^{\circledR}$ VH3100 (Buehler, USA) semi-automatic tester. Indentations were made in a $4 \times 3$ array into the surface of polished cubes. These indentations were measured using a UKAS calibrated HV0.5 kg load cell and a DiaMet ${ }^{\mathrm{TM}}$ (Buehler, USA) hardness testing software.

\section{Experimental Results}

Experimental data from each of the L-PBF and SM-L-PBF $\mathrm{AB}$ and $\mathrm{HT}$ specimen sets are presented in the following order: optimised parameters; optical density; microstructure; tensile strength; Vickers hardness.

\subsection{Single-Laser Powder Bed Fusion}

The following section presents results of $\mathrm{AB}$ and $\mathrm{HT}$ specimens manufactured by laser powder bed fusion (L-PBF) with a single laser operating alone with no other lasers firing in the machine chamber.

\subsubsection{Optimised Parameters}

Table 4 gives the L-PBF build parameters and build statistics of the L-PBF build depicted in Fig. 2.
Fig. 2 L-PBF and SM-L-PBF build setup. Build plate dimension is $250 \mathrm{~mm} \times 250 \mathrm{~mm}$. a Isometric view showing build, $\mathbf{b}$ top view (sample numbers refer to cubes only)

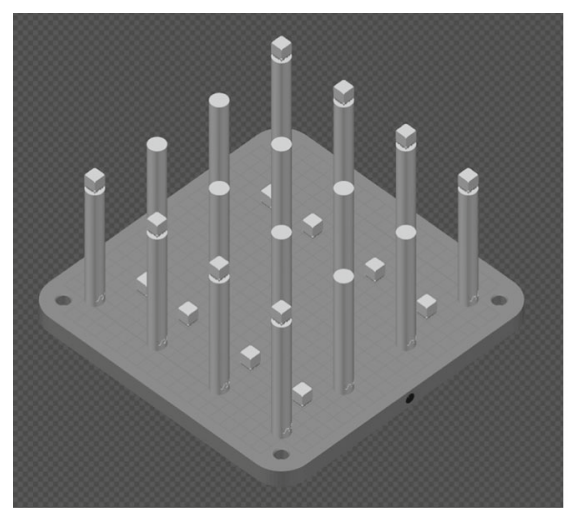

(a) isometric view showing build

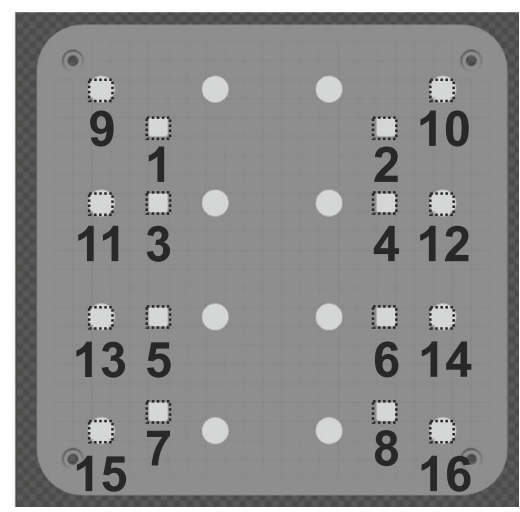

(b) top view (sample numbers refer to cubes only) 
Table 3 Characteristics of IN625 powders used in this study [8]

\begin{tabular}{|c|c|}
\hline Parameter & Value \\
\hline Metallic powder & IN625 \\
\hline Chemistry & $\begin{array}{l}\text { Nickel balanced, chromium } 20 \text { to } 23 \% \text {, molybdenum } 8 \text { to } 10 \% \text {, iron }<5 \% \text {, niobium } \\
3.15 \text { to } 4.15 \% \text {, cobalt }<1 \% \text {, copper }<0.5 \% \text {, manganese }<0.5 \% \text {, silicon }<0.5 \% \text {, } \\
\text { aluminium }<0.4 \% \text {, titanium }<0.4 \% \text {, carbon }<0.15 \% \text {, tantalum }<0.05 \% \text {, nitrogen }<\text {, }<\text {, oxygen }<0.02 \% \text {, phosporus }<0.015 \% \text {, sulphur }<0.015 \% \\
0.02 \%\end{array}$ \\
\hline Bulk density & $8.44 \mathrm{~g} / \mathrm{cm}^{3}$ \\
\hline Average tap density & $6.17 \mathrm{~g} / \mathrm{cm}^{3}$ \\
\hline $\begin{array}{l}\text { Mean size } \\
\quad \text { distribution D10 }\end{array}$ & $21.8 \mu \mathrm{m}$ \\
\hline $\begin{array}{l}\text { Mean size } \\
\quad \text { distribution D50 }\end{array}$ & $32 \mu \mathrm{m}$ \\
\hline $\begin{array}{l}\text { Mean size } \\
\text { distribution D90 }\end{array}$ & $46.5 \mu \mathrm{m}$ \\
\hline
\end{tabular}

\subsubsection{Optical Density}

Figure 3 shows the optical density result. It shows no trend in density variation across eight specimens within either $\mathrm{AB}$ or HT cubes, or between AB and HT cubes. Both sets have an average specimen bulk density of $99.99 \%$ ( 2 d.p).

\subsubsection{Microstructure}

Figures 4, 5 and 6 show the EBSD results of L-PBF cubes in the $\mathrm{XY}, \mathrm{XZ}$ and $\mathrm{YZ}$ planes. Figures $4 \mathrm{a}$ and $\mathrm{b}$ are the unique grain colour maps of the AB and HT XY cubes. Figures $4 \mathrm{c}$ and $d$ are the inverse pole figures of the $\mathrm{AB}$ and $\mathrm{HT} \mathrm{XY}$ cubes. These two plots show that there is a preferred $<001>$ crystallographic orientation parallel to the L-PBF build direction, i.e. the direction of growth. Figures $4 \mathrm{e}$ and $\mathrm{f}$ are the grain size distributions of the $\mathrm{AB}$ and HT XY cubes. These two plots indicate that most of the grain diameters are in the order of 10 $100 \mu \mathrm{m}$. Figure 5 is the EBSD result for the AB and HT cubes

Table 4 Optimised L-PBF build parameters and build statistics

\begin{tabular}{ll}
\hline Laser parameters & \\
Parameter & Value \\
Powder layer thickness $(\mu \mathrm{m})$ & 30 \\
Peak power $(\mathrm{W})$ & 200 \\
Exposure time $(\mu \mathrm{s})$ & 70 \\
Spot size $($ full-width-half-maximum) $(\mu \mathrm{m})$ & 80 \\
Point distance $(\mu \mathrm{m})$ & 70 \\
Hatch distance $(\mu \mathrm{m})$ & 90 \\
Build statistics & \\
Parameter & Value \\
Specimen type & Cube, cylinder \\
Specimen volume processed $\left(\mathrm{cm}^{3}\right)$ & 262 \\
Build time $\left(\mathrm{rounded}^{3}\right.$ to nearest hour $)$ & 52 \\
Build rate $\left(\mathrm{cm}^{3} / \mathrm{h}\right)$ & 5 \\
\hline
\end{tabular}

in XZ plane whilst Fig. 6 is that of the YZ plane. Results in these two planes are similar and will be presented together in this paragraph. Figures 5 and $6 \mathrm{a}$ and $\mathrm{b}$ are the unique grain colour maps of the AB and HT XZ and YZ cubes. These four figures show that the columnar grains show a preferential growth direction parallel to the L-PBF build direction. Figures 5 and $6 \mathrm{c}$ and $\mathrm{d}$ are the inverse pole figures of the $\mathrm{AB}$ and HT XZ and YZ cubes. Discrete intensity maxima in the $<001>$ crystallographic orientation can be observed in both north and south poles of the four figures. This observation supports the argument which postulates that the preferential growth direction is parallel to the L-PBF build direction. Figures 5 and $6 \mathrm{e}$ and $\mathrm{f}$ are the grain size distributions of the $\mathrm{AB}$ and HT XZ and YZ cubes. The two plots indicate that most of the grain diameters are of the order of 10 to $100 \mu \mathrm{m}$.

\subsubsection{Tensile Strength}

Table 5 and Fig. 7 summarise the tensile behaviour of the LPBF AB and HT cylinders. The standard error values of the ultimate tensile strength (UTS), $0.2 \%$ offset yield strength

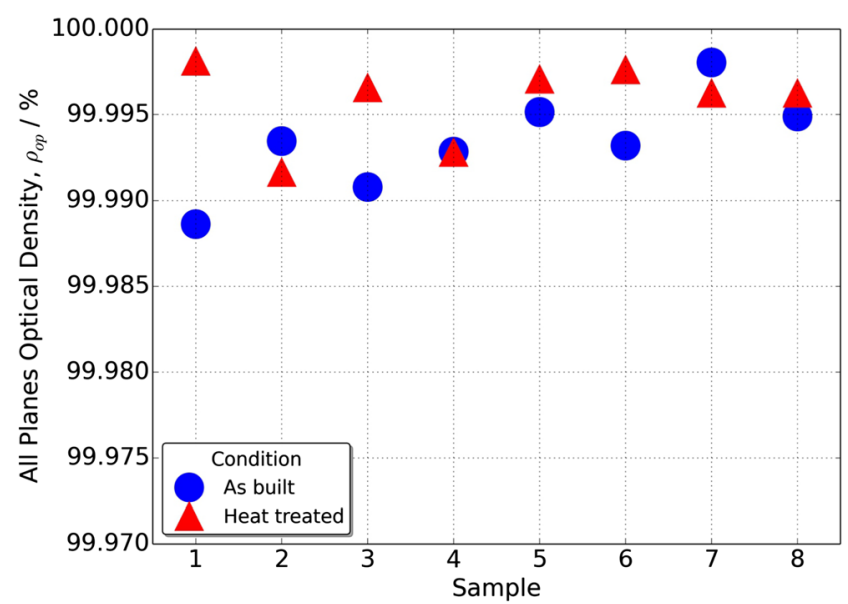

Fig. 3 Optical density of the AB and HT specimens manufactured by LPBF 


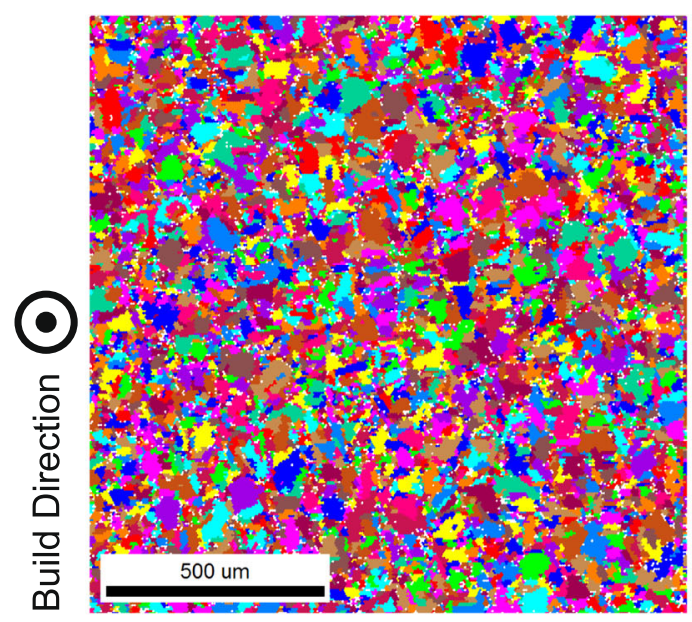

(a) Unique grain colour map, $\mathrm{AB}$
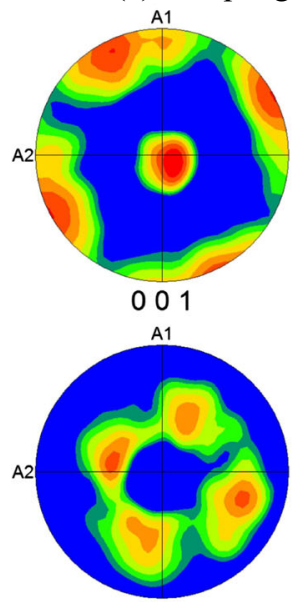

111

(c) Inverse pole figure, $\mathrm{AB}$

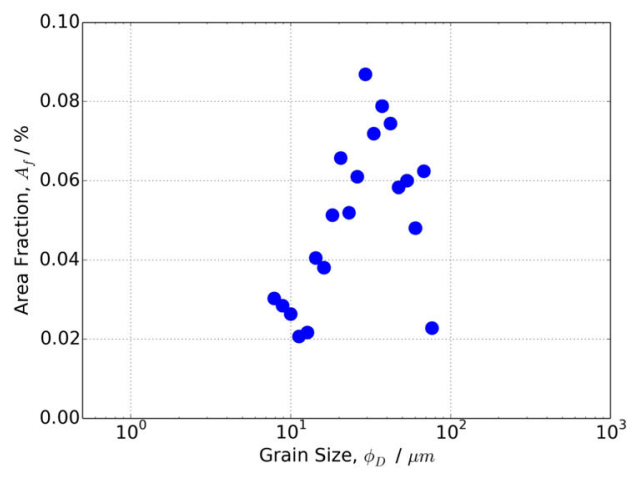

(e) Inverse pole figure, $\mathrm{AB}$

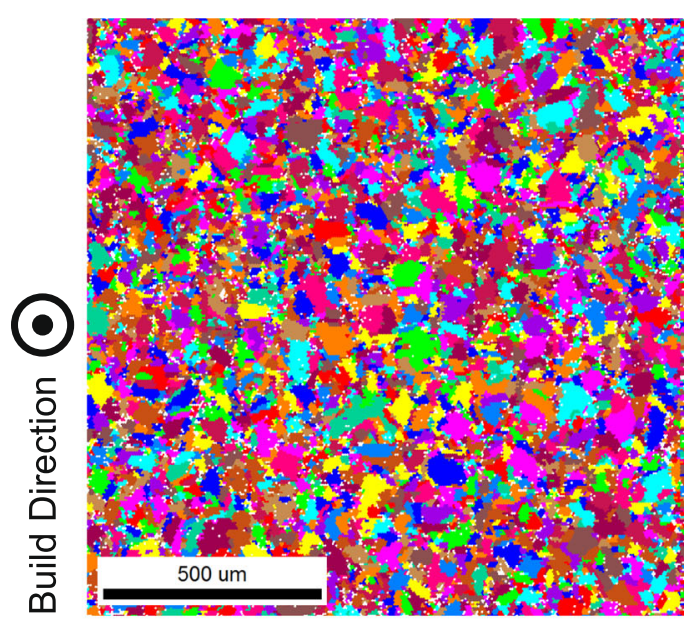

(b) Unique grain colour map, HT
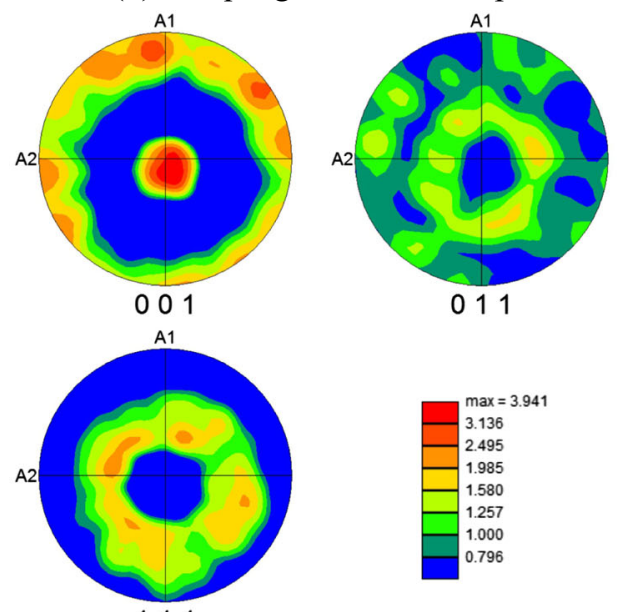

111

(d) Inverse pole figure, HT

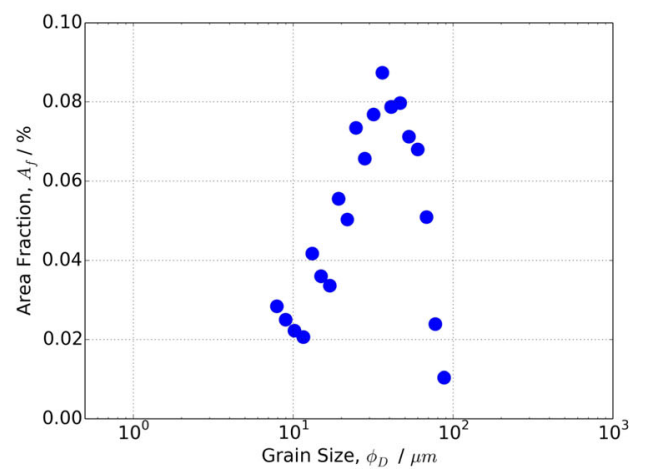

(f) Inverse pole figure, HT

Fig. 4 L-PBF EBSD results-XY plane. a Unique grain colour map, AB; $\mathbf{b}$ unique grain colour map, HT; $\mathbf{c}$ inverse pole figure, AB; $\mathbf{d}$ inverse pole figure, HT; e inverse pole figure, AB; (f) inverse pole figure, HT

(YS) and elongation within both $\mathrm{AB}$ and HT sets were insignificant when compared to their average values; this shows that the specimen sets had similar tensile behaviour within each set. Figure 7 depicts that the HT set has lower UTS, lower $0.2 \%$ offset YS and greater elongation when compared to those of the AB set.

\subsubsection{Vickers Hardness}

Figure 8 gives the hardness of the L-PBF AB and HT cubes. The average AB and HT Vickers hardness values were 261.91 HV0.5 (2 d.p) and 269.97 HV0.5 (2 d.p). HV0.5 is the unit in which 0.5 indicates the load used in kgf. Average standard 


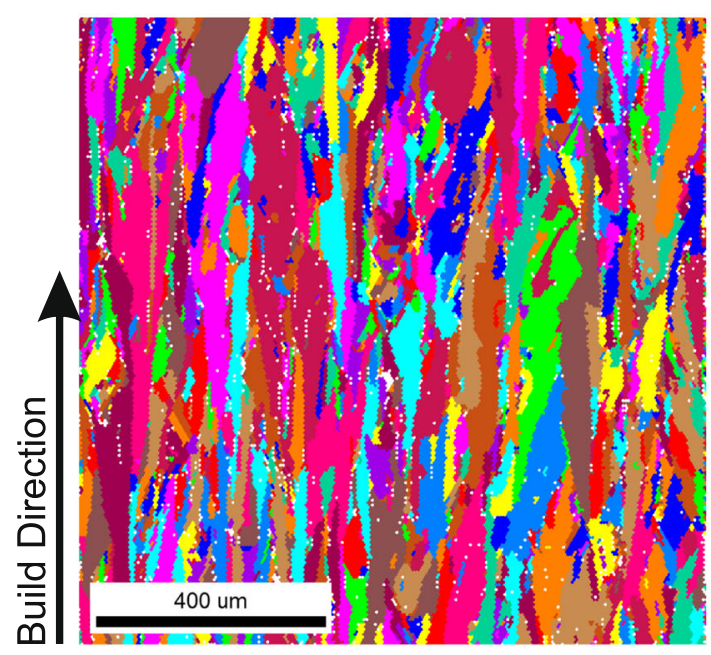

(a) Unique grain colour map, AB

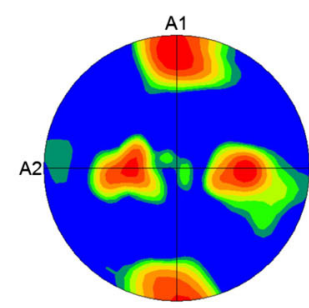

001

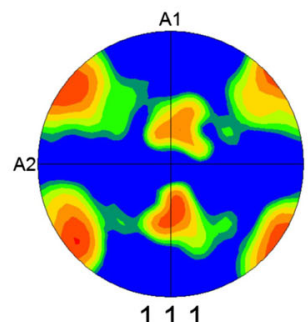

(c) Inverse pole figure, $\mathrm{AB}$

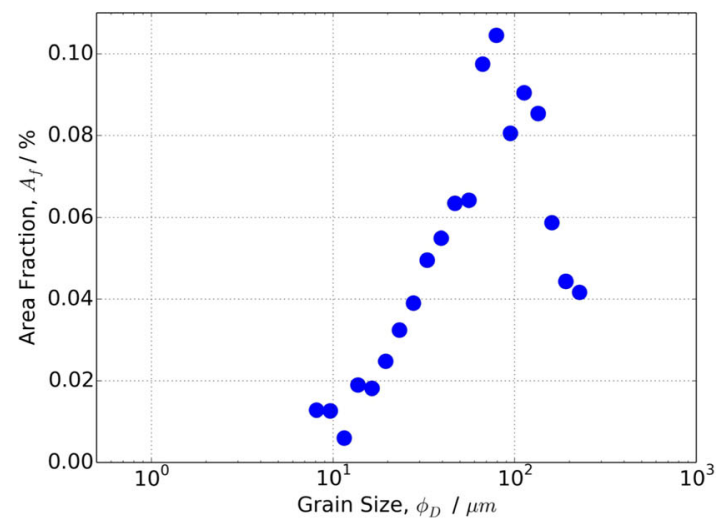

(e) Inverse pole figure, $\mathrm{AB}$

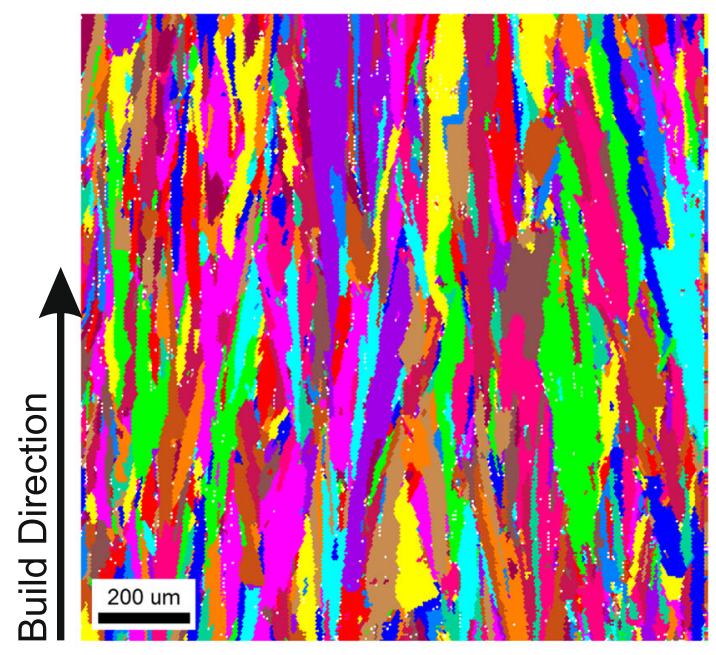

(b) Unique grain colour map, HT
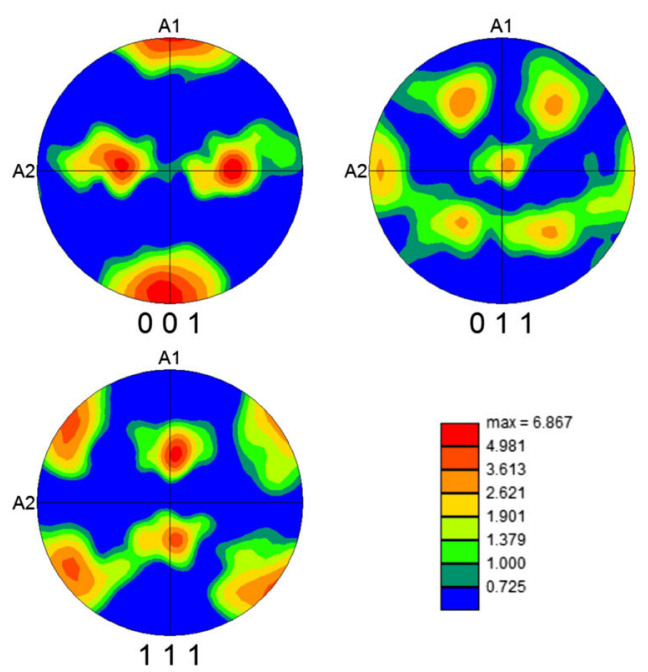

(d) Inverse pole figure, HT

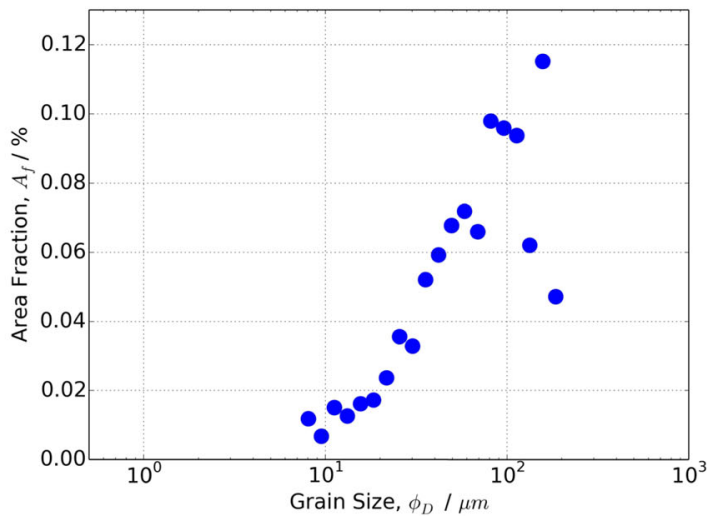

(f) Inverse pole figure, HT

Fig. 5 L-PBF EBSD results - XZ plane. a Unique grain colour map, AB; $\mathbf{b}$ unique grain colour map, HT; $\mathbf{c}$ inverse pole figure, AB; $\mathbf{d}$ inverse pole figure, HT; e inverse pole figure, AB; $\mathbf{f}$ inverse pole figure, $\mathrm{HT}$ 


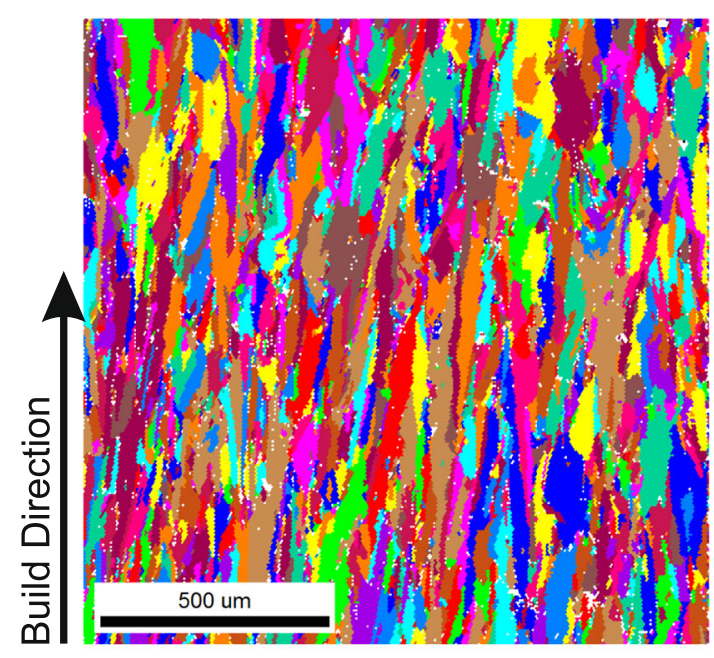

(a) Unique grain colour map, $\mathrm{AB}$
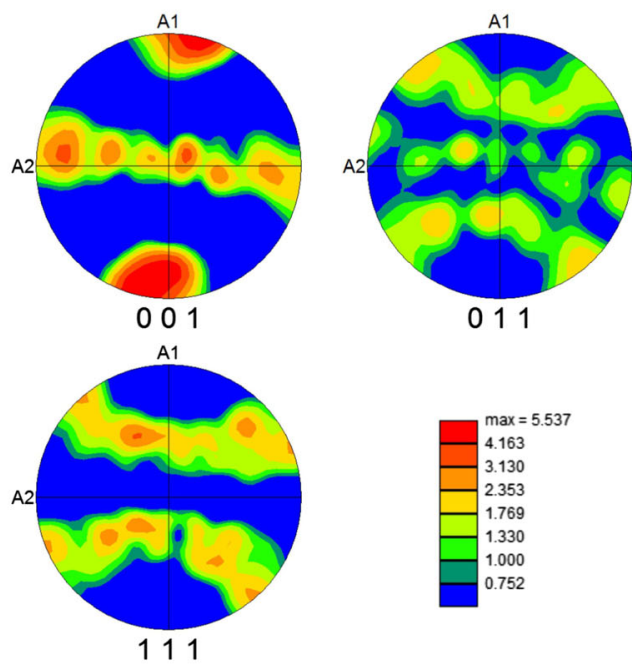

(c) Inverse pole figure, $\mathrm{AB}$

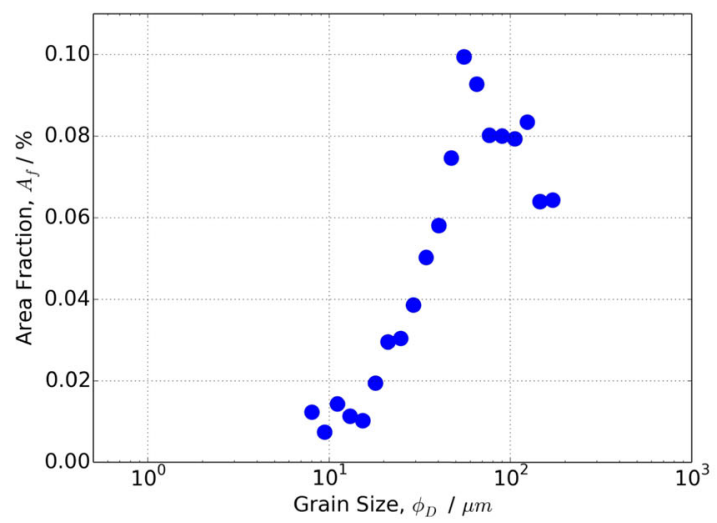

(e) Inverse pole figure, $A B$

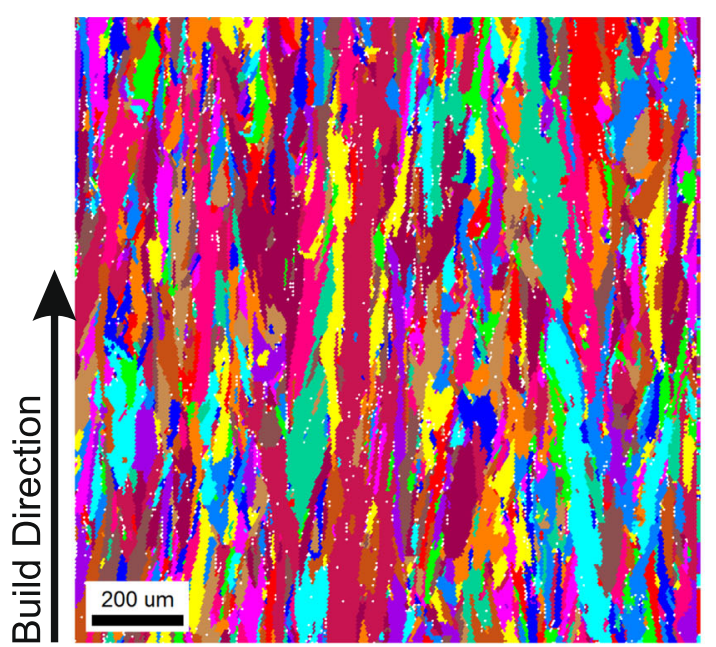

(b) Unique grain colour map, HT
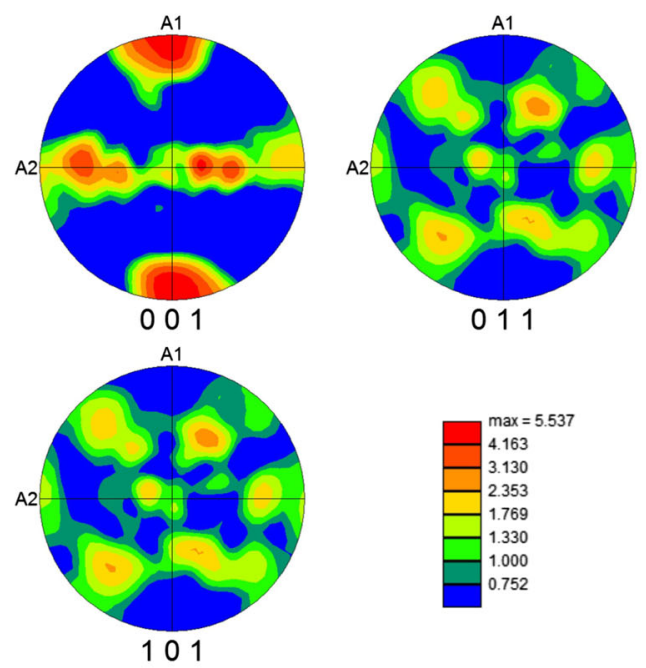

(d) Inverse pole figure, HT

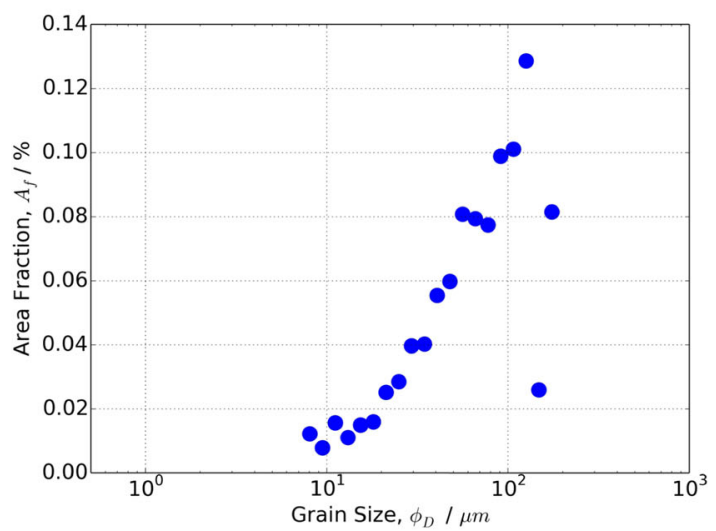

(f) Inverse pole figure, HT

Fig. 6 L-PBF EBSD results-YZ plane. a Unique grain colour map, AB; $\mathbf{b}$ unique grain colour map, HT; $\mathbf{c}$ inverse pole figure, AB; $\mathbf{d}$ inverse pole figure, HT; e inverse pole figure, AB; f inverse pole figure, HT 
Table $5 \mathrm{AB}$ and HT specimen average tensile behaviour. Data rounded to 3 s.f

\begin{tabular}{|c|c|c|c|c|c|c|}
\hline Specimen & $\mathrm{UTS} / \mathrm{MPa}$ & UTS standard error/MPa & $0.2 \%$ offset $\mathrm{YS} / \mathrm{MPa}$ & $\begin{array}{l}0.2 \% \text { offset } \mathrm{YS} \text { standard } \\
\text { error/MPa }\end{array}$ & Elongation $/ \%$ & Elongation standard error $/ \%$ \\
\hline AB cylinders & 901 & 1.03 & 619 & 0.734 & 56.7 & 0.0971 \\
\hline HT cylinders & 841 & 0.574 & 523 & 0.425 & 68.5 & 0.150 \\
\hline
\end{tabular}

error (error bars in plot) calculated for the AB and HT set were 2.77 ( 2 d.p) and 2.74 (2 d.p). Comparison between $A B$ and HT specimen sets in the figure shows that some specimens have greater hardness after heat treatment.

\subsection{Single-Multi Laser Powder Bed Fusion}

The following section presents the results of $\mathrm{AB}$ and HT specimens manufactured by laser powder bed fusion (L-PBF) with four lasers firing in the machine chamber.

\subsubsection{Optimised Parameters}

Table 6 gives the SM-L-PBF build parameters and statistics of the SM-L-PBF build depicted in Fig. 2.

\subsubsection{Optical Density}

Figure 9 shows no trend in density variation across eight specimens within either $\mathrm{AB}$ or $\mathrm{HT}$ cubes, and between $\mathrm{AB}$ and $\mathrm{HT}$ cubes. Both sets have an average specimen bulk density of $99.99 \%$ (2 d.p).

\subsubsection{Microstructure}

Figures 10, 11 and 12 show the EBSD results of SM-L-PBF cubes. Figures 10,11 and $12 \mathrm{a}$ and $\mathrm{b}$ are the unique grain colour maps of the $\mathrm{AB}$ and $\mathrm{HT}$ cubes in the $\mathrm{XY}, \mathrm{XZ}$ and $\mathrm{YZ}$

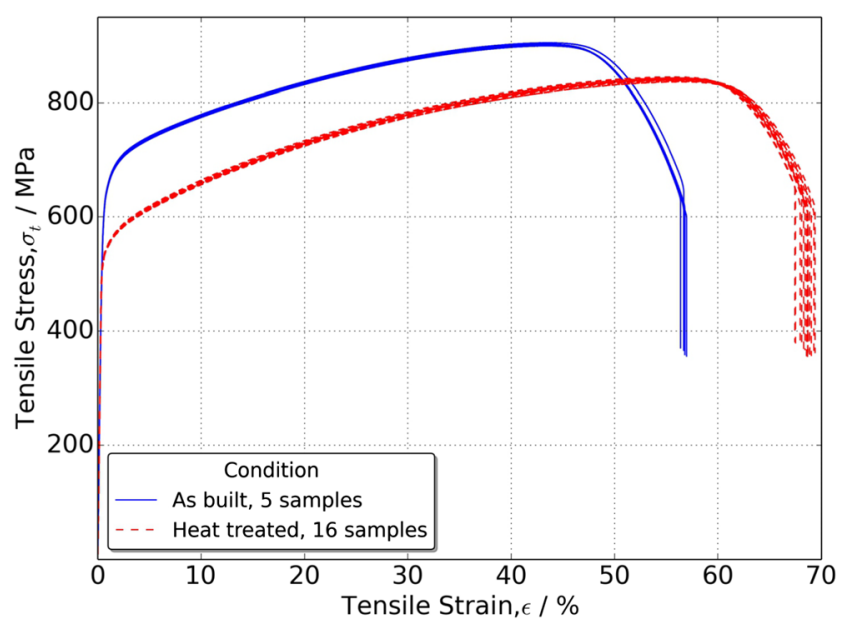

Fig. 7 Tensile strength of the AB and HT specimens manufactured by LPBF planes. Figures 10,11 and $12 \mathrm{c}$ and $\mathrm{d}$ are the inverse pole figures of the $\mathrm{AB}$ and HT cubes in the three planes. These SM-L-PBF results show the same key features as those of the L-PBF described in Section 3.1.3: (1) the <001> crystallographic orientation patterns of the AB/HT XY, XZ and YZ plane datasets indicate that the microstructure has a preferential grain growth direction parallel to the build direction, and (2) the grain diameters are of the order of 10 to $100 \mu \mathrm{m}$.

\subsubsection{Tensile Strength}

Table 7 and Fig. 13 summarise the tensile behaviour of the SM-L-PBF AB and HT cylinders. The standard error values of the UTS, $0.2 \%$ offset yield and elongation in both AB and HT sets were insignificant when compared to their average values, this showed that the specimen sets had similar tensile behaviour within each set. Figure 12 depicts that the HT set has lower UTS, lower $0.2 \%$ offset YS and greater elongation when compared to those of the $\mathrm{AB}$ set.

\subsubsection{Vickers Hardness}

Figure 14 gives the hardness of the SM-L-PBF AB and HT cubes. The average $\mathrm{AB}$ and HT Vickers hardness values were found to be 284.25 HV0.5 ( 2 d.p) and 271.08 HV0.5 (2 d.p). Average standard error (error bars in plot) calculated for the $\mathrm{AB}$ and HT set were 2.35 (2dp) and 2.25 (2 d.p). Comparison

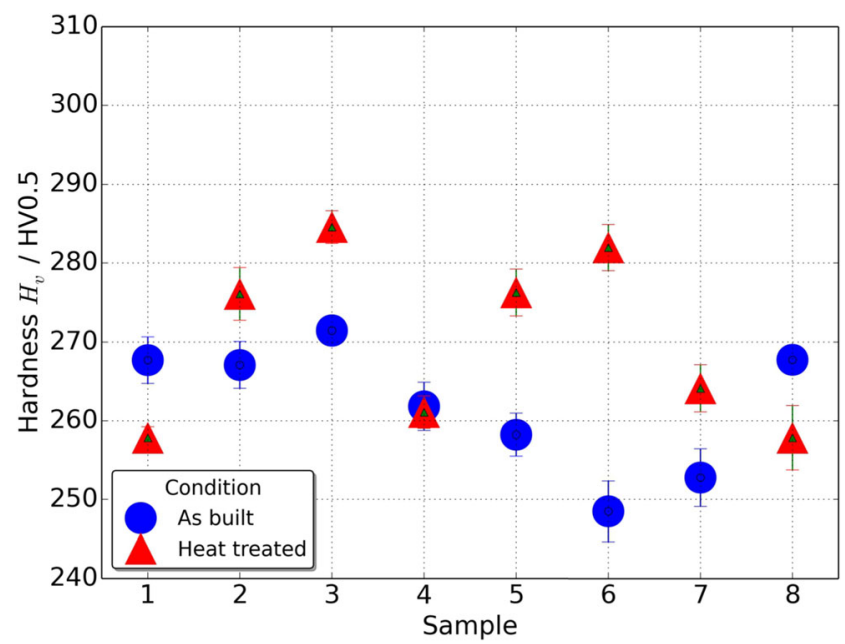

Fig. 8 Vickers hardness of the $\mathrm{AB}$ and HT specimens manufactured by LPBF 
Table 6 Optimised SM-L-PBF build parameters and build statistics

\begin{tabular}{ll} 
Laser parameters & \\
Parameter & Value \\
Powder layer thickness $(\mu \mathrm{m})$ & 30 \\
Peak power $(\mathrm{W})$ & 200 \\
Exposure time $(\mu \mathrm{s})$ & 70 \\
Spot size $($ full-width-half-maximum) $(\mu \mathrm{m})$ & 80 \\
Point distance $(\mu \mathrm{m})$ & 70 \\
Hatch distance $(\mu \mathrm{m})$ & 90 \\
Build statistics & \\
Parameter & Value \\
Specimen type & Cube, cylinder \\
Specimen volume processed $\left(\mathrm{cm}^{3}\right)$ & 262 \\
Build time $(\mathrm{rounded}$ to nearest hour $)$ & 19 \\
Build rate $\left(\mathrm{cm}^{3} / \mathrm{h}\right)$ & 14 \\
\hline
\end{tabular}

between $\mathrm{AB}$ and $\mathrm{HT}$ specimen sets in the figure shows a general reduction in hardness after heat treatment.

\section{Discussion}

In this section, analyses on mechanical properties for the LPBF and SM-L-PBF, AB and HT specimen sets are made. Comparisons between L-PBF and SM-L-PBF are only made on HT specimens as only stress-relieved components are used in commercial applications with IN625.

\subsection{Optical Density}

The four L-PBF/SM-L-PBF, AB/HT datasets have an average specimen density of $99.99 \%$ ( 2 d.p). Variations in density between the AB and HT sets, in both L-PBF and SM-PBF, are all less than $0.01 \%$, this implies that the heat treatment

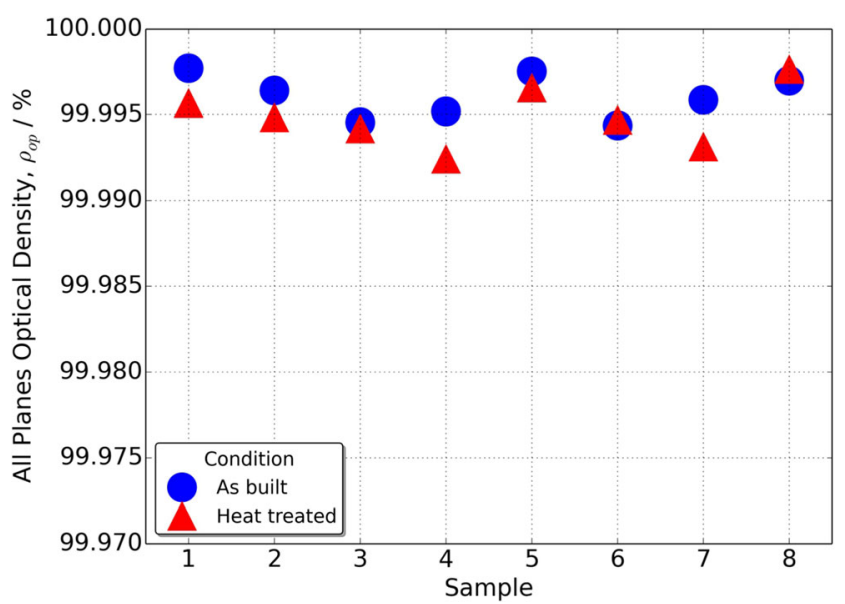

Fig. 9 Optical density of the AB and HT cubes manufactured by SM-LPBF process carried out in this study did not influence specimen density. The density result achieved in this study is on a par with or exceeds values reported (98.5 to $99.5 \%$ ) in the literature on L-PBF IN625 specimens [14].

\subsection{Microstructure}

Figures 4, 5 and $6 \mathrm{a}-\mathrm{f}$ and Figs. 10, 11 and $12 \mathrm{a}-\mathrm{f}$ show that both the stress-relieving heat treatment and the multi-laser arrangements have little to no effect on the microstructure of the specimens. The unique grain colour maps and the inverse pole figures of the $\mathrm{XY}, \mathrm{XZ}$ and $\mathrm{YZ}$ planes in the $\mathrm{AB} / \mathrm{HT}$, L$\mathrm{PBF} / \mathrm{SM}-\mathrm{PBF}$ datasets demonstrate that the preferred crystallographic orientation of columnar grains growth is parallel to the L-PBF build direction. This observation is in line with other experimental results in the literature [15]. Results show that the grain size from the AB/HT, L-PBF/SM-L-PBF datasets is of the order of 10 to $100 \mu \mathrm{m}$. This grain size range also matches other experimental results reported in the literature [16].

\subsection{Tensile Strength}

Variation in the standard error values between the four L-PBF, SM-L-PBF, AB and HT data sets were insignificant. This shows that the specimen sets have similar tensile behaviour within each set. The cylinders were built in the configuration described in Fig. 2. The build layout and the low CV values indicate that the specimen tensile strength is independent of build location across the machine processing area. Figure 7 depicts that the L-PBF HT set has lower UTS, lower $0.2 \%$ offset YS and greater elongation when compared to those of the L-PBF AB set. It is thought that these HT cylinders were more ductile when compared to the AB cylinders. Similar to the tensile behaviour in L-PBF, Fig. 13 depicts that the SM-LPBF HT set also has lower UTS, lower $0.2 \%$ offset YS and greater elongation when compared to those of the SM-L-PBF $\mathrm{AB}$ set.

The increase in ductility is attributed to the heat treatment process carried out in this study. L-PBF manufactured specimens suffer from thermal residual stress and melted areas were plastically deformed and work-hardened under stress $[17,18]$. Heat treatment relieves thermal residual stress. Thus, HT cylinders are easier to deform when compared to $\mathrm{AB}$ cylinders. This results in greater strain under the same level of stress, lower UTS, $0.2 \%$ offset YS and greater elongation before fracture, when compared to $\mathrm{AB}$ cylinders.

Table 8 is compiled by drawing data from Tables 5 and 7 and both ASTM B564 and B446 standards [19, 20]. Results show that the tensile behaviour of L-PBF HT and SM-L-PBF HT cylinders are comparable. The percentage differences on UTS, $0.2 \%$ YS and elongation and between the L-PBF HT and SM-L-PBF HT cylinders are 1.7\%, 3.2\% and 1.2\% 


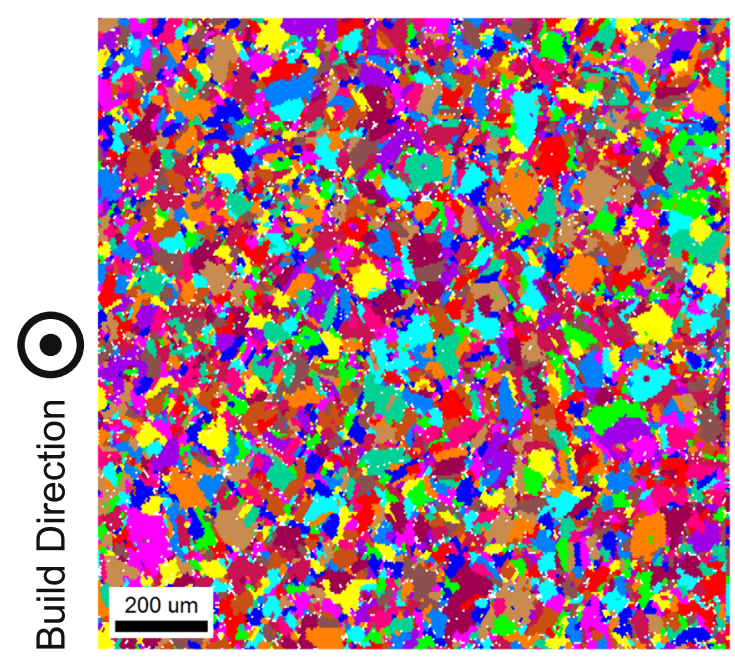

(a) Unique grain colour map, $\mathrm{AB}$
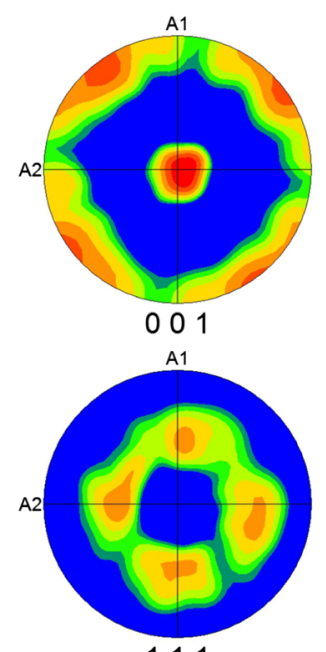

111
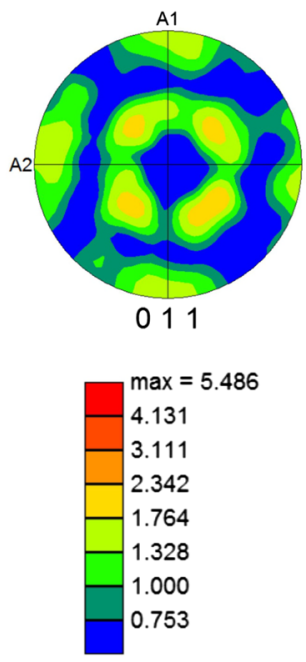

(c) Inverse pole figure, $\mathrm{AB}$

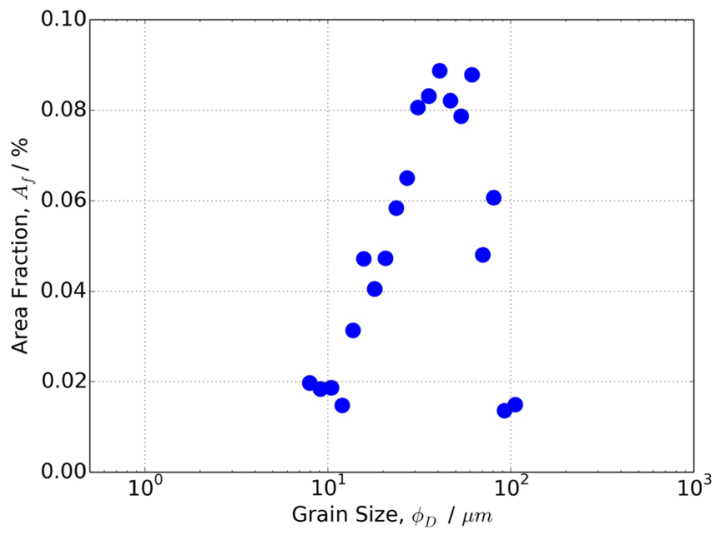

(e) Grain size distribution, AB

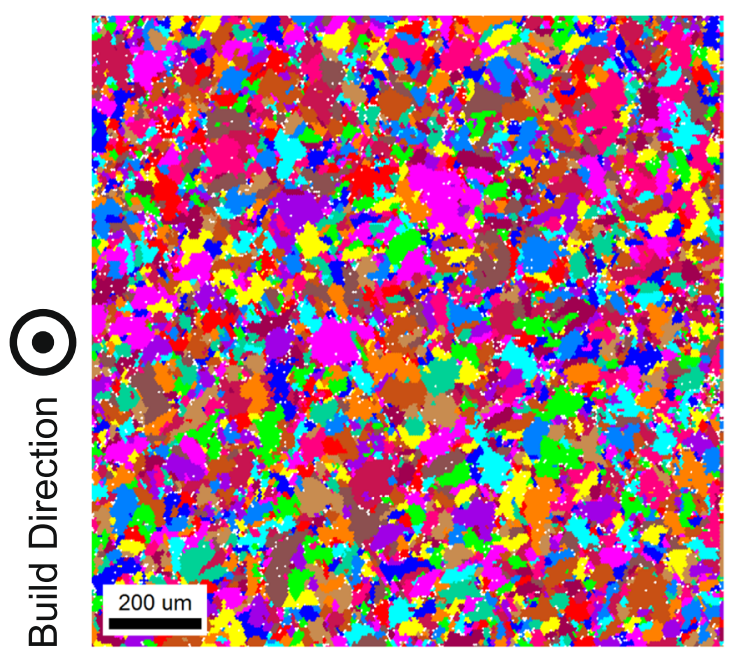

(b) Unique grain colour map, HT
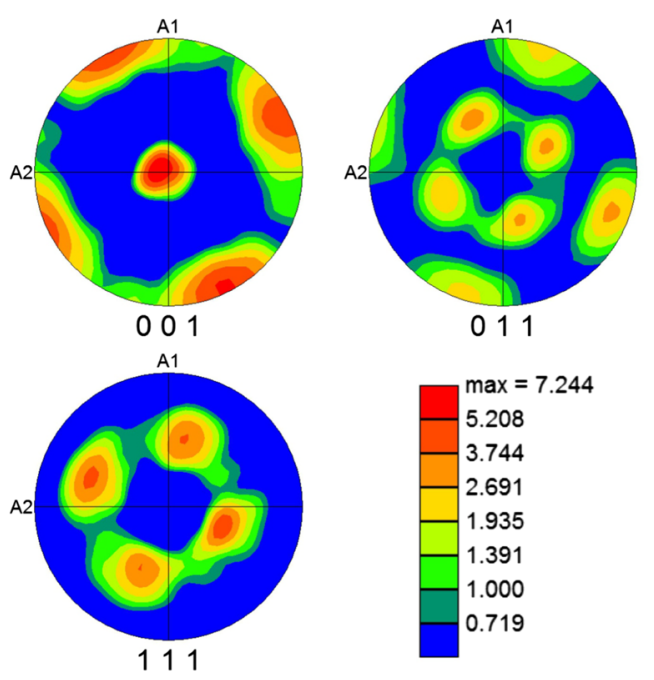

(d) Inverse pole figure, HT

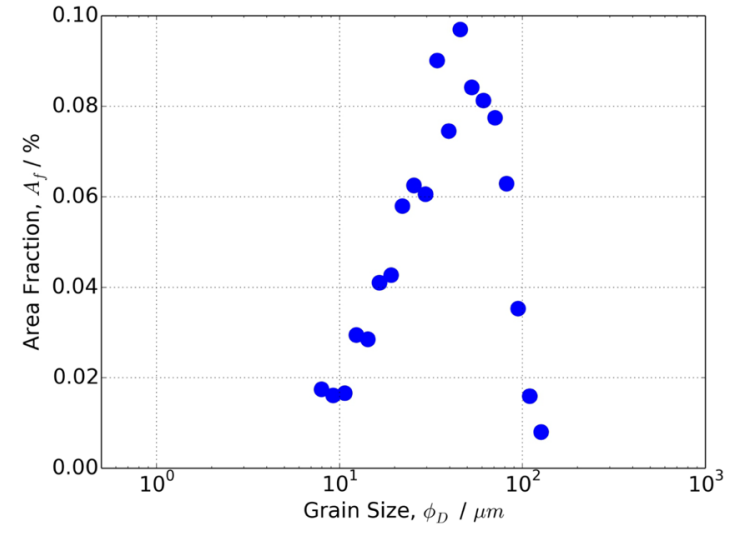

(e) Grain size distribution, HT

Fig. 10 SM-L-PBF EBSD results - XY plane. a Unique grain colour map, AB; b unique grain colour map, HT; $\mathbf{c}$ inverse pole figure, AB; $\mathbf{d}$ inverse pole figure, HT; e grain size distribution, AB; $\mathbf{f}$ grain size distribution, HT

respectively. Although only by a small margin, SM-L-PBF HT cylinders appear to have lower UTS and $0.2 \%$ offset YS, and greater elongation when compared to L-PBF HT cylinders. This suggests that the L-PBF cylinders had greater 


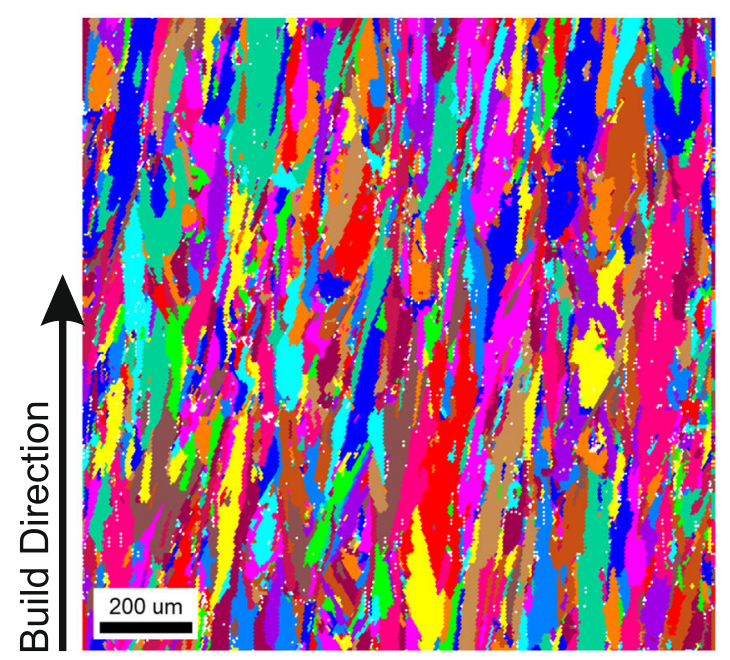

(a) Unique grain colour map, $\mathrm{AB}$
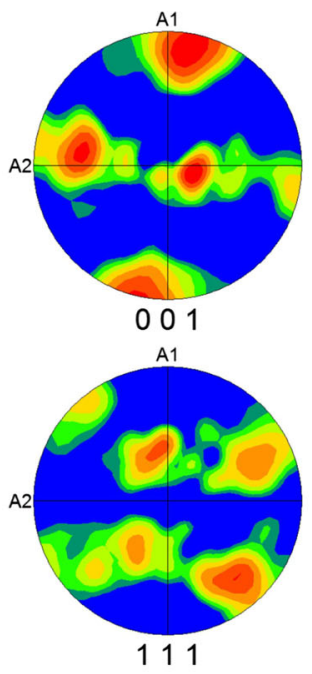

(c) Inverse pole figure, $\mathrm{AB}$

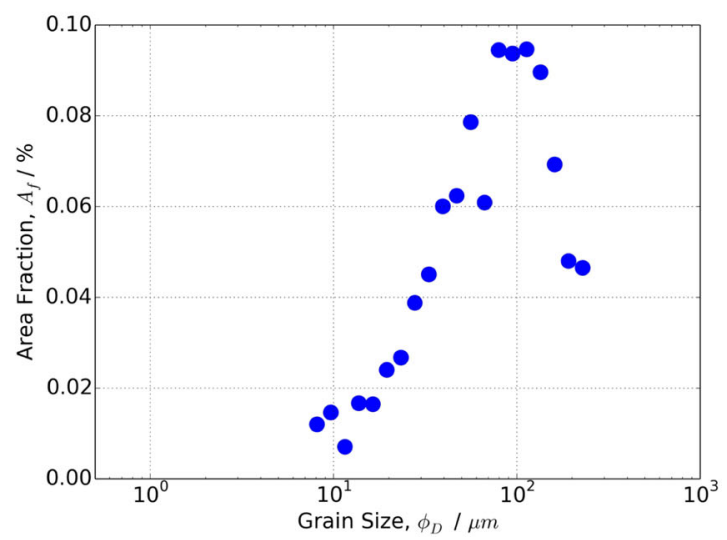

(e) Inverse pole figure, $\mathrm{AB}$

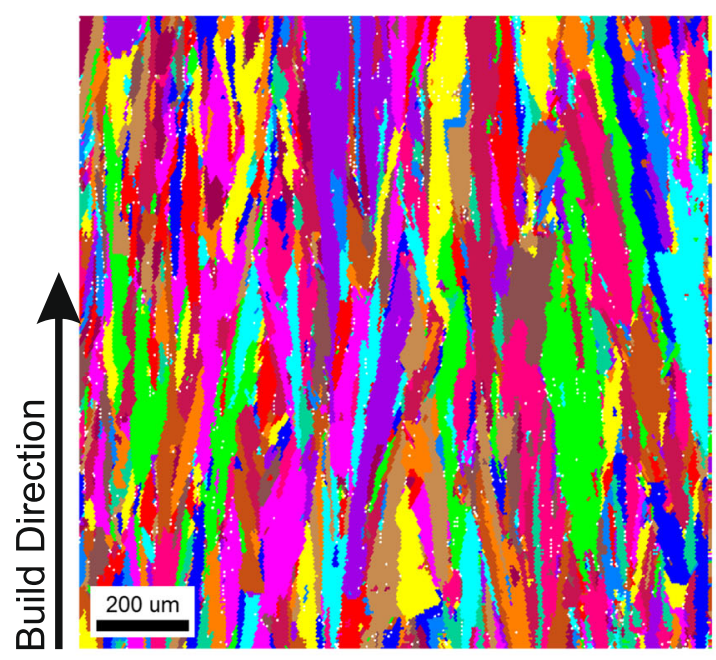

(b) Unique grain colour map, HT
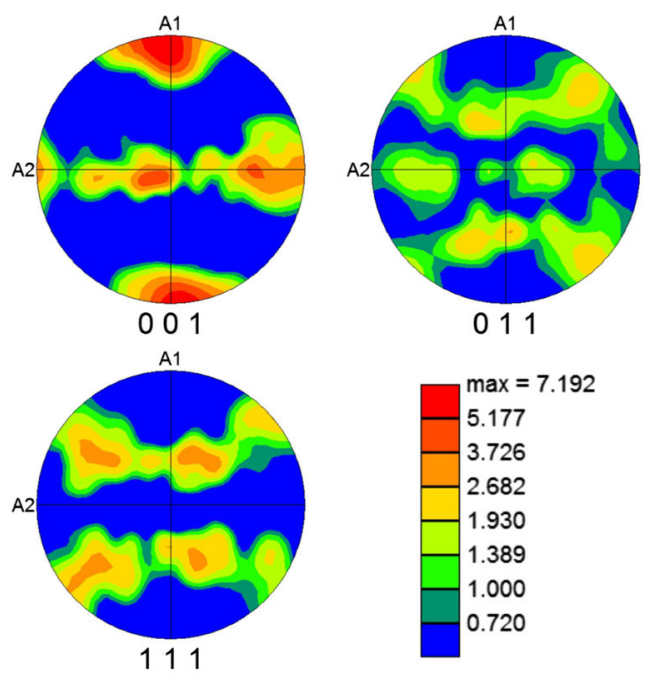

(d) Inverse pole figure, HT

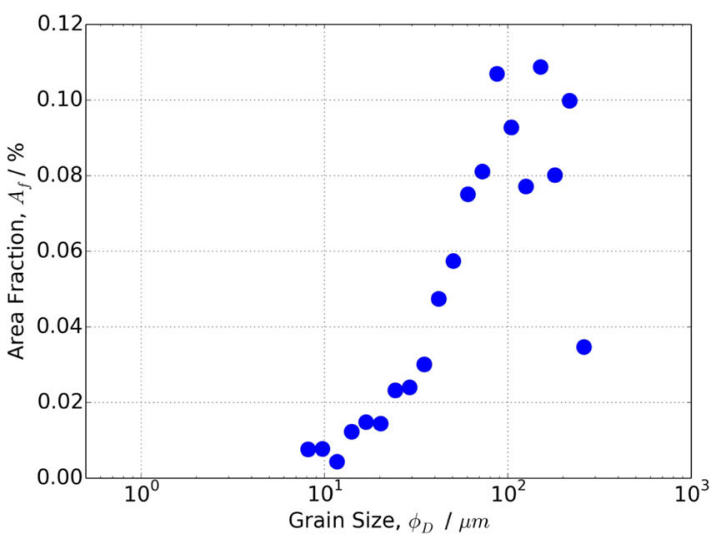

(f) Inverse pole figure, HT

Fig. 11 SM-L-PBF EBSD results—XZ plane; a Unique grain colour map, AB; $\mathbf{b}$ unique grain colour map, HT; $\mathbf{c}$ inverse pole figure, AB; $\mathbf{d}$ inverse pole figure, $\mathrm{HT}$; $\mathbf{e}$ inverse pole figure, $\mathrm{AB}$; $\mathbf{f}$ inverse pole figure, $\mathrm{HT}$ 


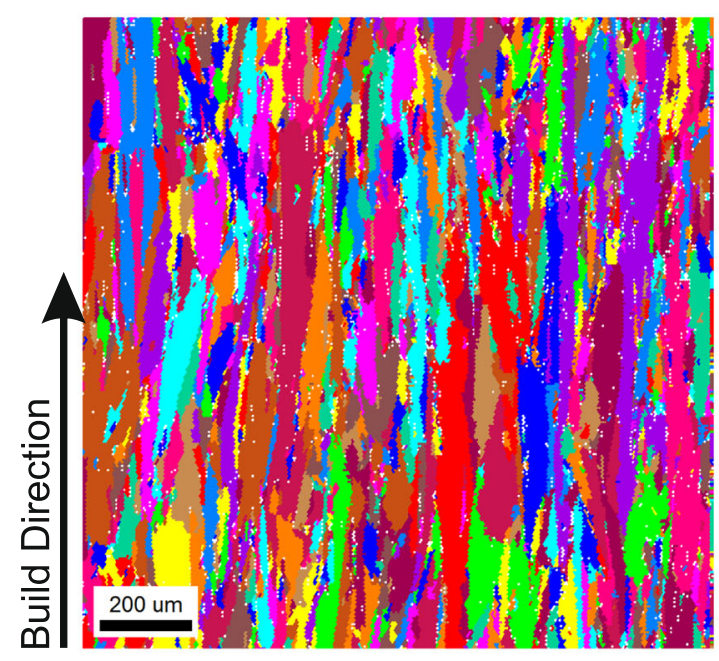

(a) Unique grain colour map, $\mathrm{AB}$

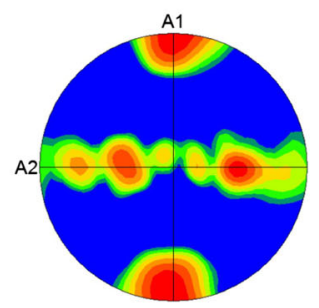

001

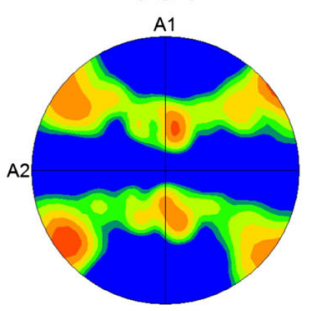

111
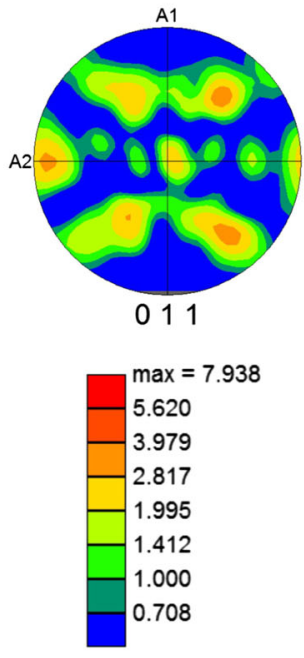

(c) Inverse pole figure, $\mathrm{AB}$

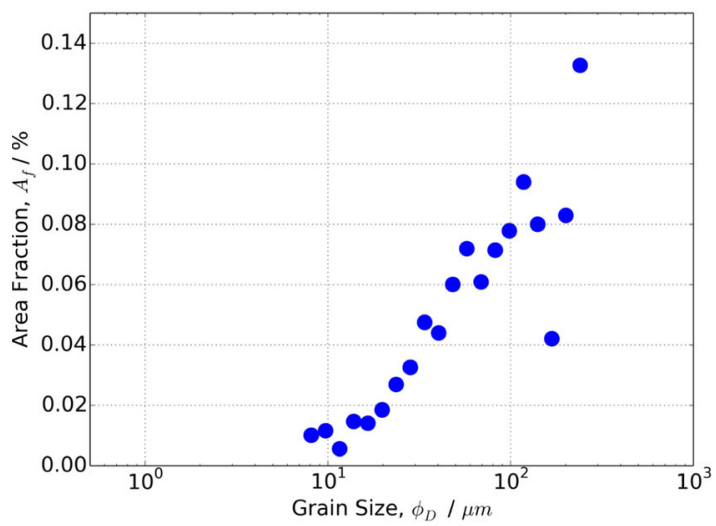

(e) Inverse pole figure, $\mathrm{AB}$

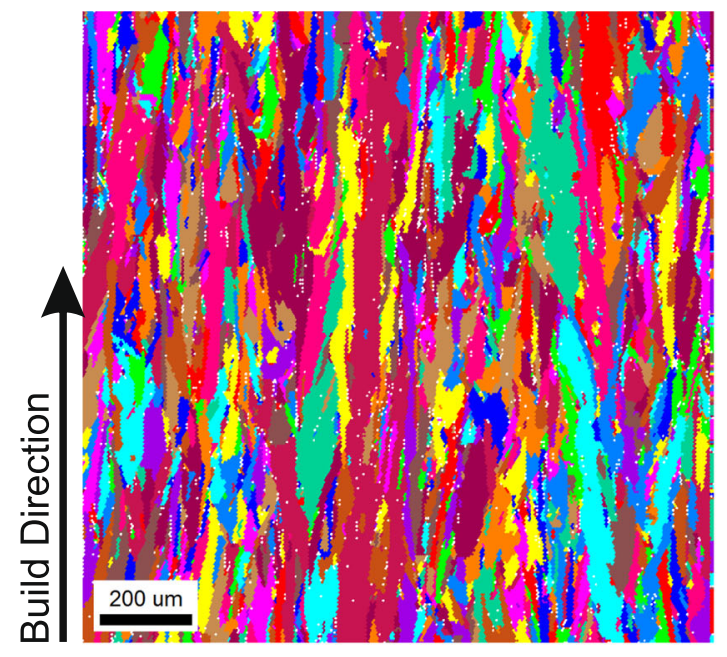

(b) Unique grain colour map, HT
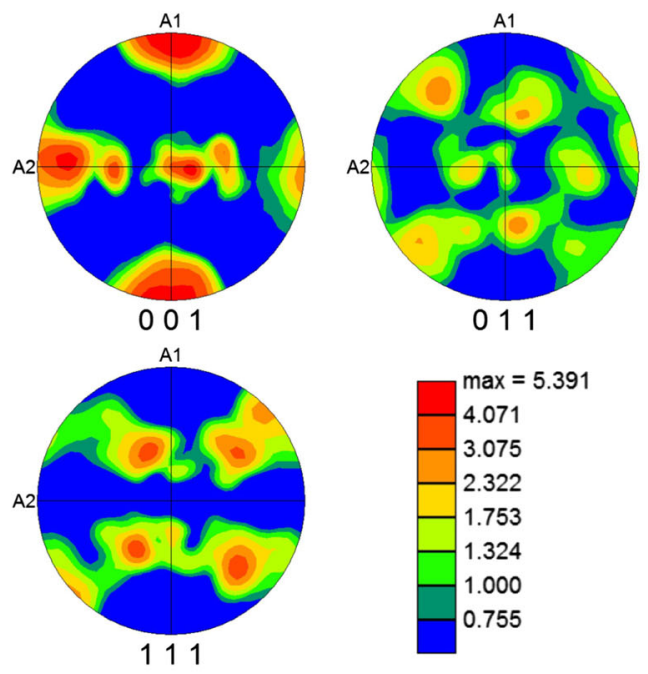

(d) Inverse pole figure, HT

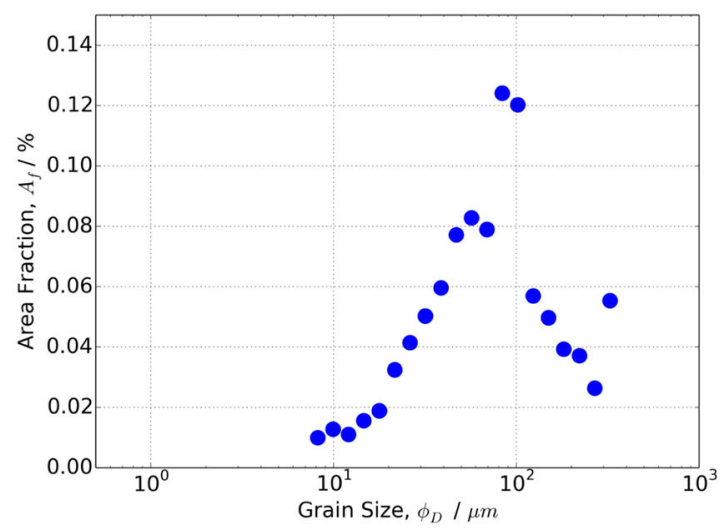

(f) Inverse pole figure, HT

Fig. 12 SM-L-PBF EBSD results-YZ plane. a Unique grain colour map, AB; $\mathbf{b}$ unique grain colour map, HT; $\mathbf{c}$ inverse pole figure, AB; $\mathbf{d}$ inverse pole figure, $\mathrm{HT} ; \mathbf{e}$ inverse pole figure, $\mathrm{AB} ; \mathbf{f}$ inverse pole figure, $\mathrm{HT}$

residual tensile stress. As the average processed layer time in a L-PBF build is greater than that of a SM-L-PBF build, the time interval for any component to be worked by the laser is greater in L-PBF. This is believed to have led to a longer 
Table $7 \quad \mathrm{AB}$ and HT specimen average tensile behaviour. Data are rounded to 3 s.f

\begin{tabular}{lllllll}
\hline Specimen & UTS/MPa & $\begin{array}{l}\text { UTS standard } \\
\text { error/MPa }\end{array}$ & $\begin{array}{l}0.2 \% \text { offset YS } \\
\text { standard error/MPa }\end{array}$ & $\begin{array}{l}\text { Offset YS standard } \\
\text { error/MPa }\end{array}$ & $\begin{array}{l}\text { Elongation/\% } \\
\begin{array}{l}\text { Elongation } \\
\text { standard error/\% }\end{array}\end{array}$ \\
\hline AB cylinders & 864 & 0.700 & 585 & 0.393 & 58.6 & 0.100 \\
HT cylinders & 827 & 0.726 & 507 & 0.493 & 69.3 & 0.0750 \\
\hline
\end{tabular}

cooling time between layers for the L-PBF cylinders. Moreover, Table 8 also shows that L-PBF and SM-L-PBF HT cylinders tensile properties either meet or exceed the tensile requirements set out by ASTM standards on IN625 components manufactured by conventional methods.

\subsection{Vickers Hardness}

All cubes from the four L-PBF/SM-L-PBF and AB/HT datasets involved in hardness test underwent 12 hardness measurements on the Vickers hardness machine. The average standard error (error bar in Figs. 8 and 14) of all four datasets is less than $2.8 \%$. The low standard error values imply that the hardness measurements are consistent.

Figure 8 shows that L-PBF/SM-L-PBF AB and HT cubes have similar hardness. The maximum difference in hardness between the L-PBF/SM-L-PBF AB and HT cube is less than $7 \%$. Results also show that the hardness property of L-PBF HT and SM-L-PBF HT cubes are comparable, the difference in their average Vickers hardness is less than $1 \%$ (data from Sections 3.1.5 and 3.2.5). In addition, the average hardness achieved in this study is in the same order, 280HV0.5, of that reported in literature on L-PBF nickel alloy specimens [21].

When compared to the AB/HT SM-L-PBF dataset (Fig. 14), the AB/HT L-PBF dataset (Fig. 8) shows that the hardness values scatter more across the eight cube samples. Figure 2 shows that cube 1 to 8 were built directly on the build

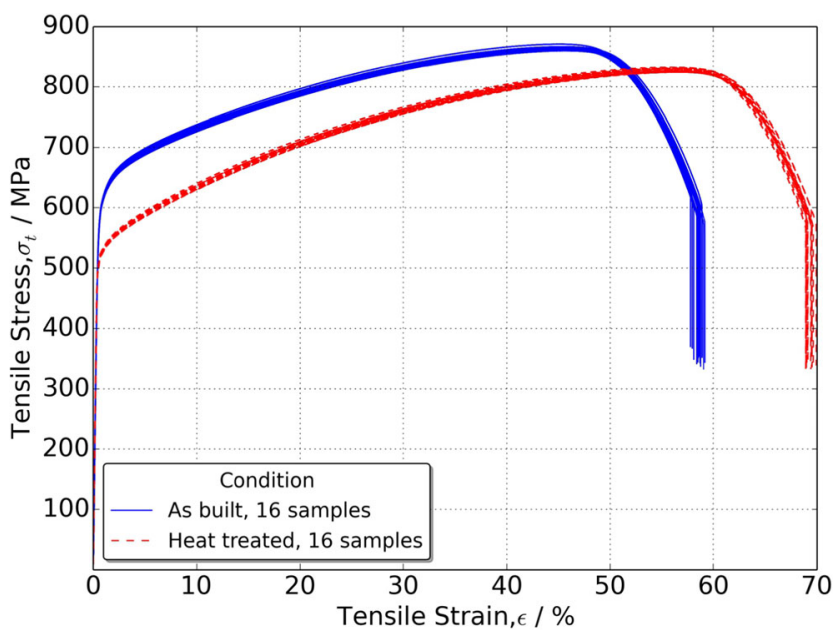

Fig. 13 Tensile strength of the AB and HT specimens manufactured by SM-L-PBF plate alongside the cylinders, whilst cubes 9 to 16 were built on top of the cylinders. The inter-layer laser melting time interval for cubes 1 to 8 was different from that of cubes 9 to 16 , as there were 24 components to process when cubes 1 to 8 were manufactured ( 8 cubes and 16 cylinders) whilst there were only 8 to process when cube $9-16$ were manufactured ( 8 cubes only). Although this situation was the same for both LPBF and SM-L-PBF, the inter-layer time interval was less in SM-L-PBF as there were four material processing lasers. It is thought that the greater time interval in L-PBF might have played a role affecting the hardness in the cubes, leading to greater variation when compared to that of the SM-L-PBF dataset.

\subsection{Build Rate}

Results show that, for an IN625 build at 30- $\mu$ m layer thickness, the build rate of SM-L-PBF arrangement is $14 \mathrm{~cm}^{3} / \mathrm{h}$ whilst that of the L-PBF is $5 \mathrm{~cm}^{3} / \mathrm{h}$. The SM-L-PBF build rate is 2.74 times higher, and the production time saved due to the high throughput of the SM-L-PBF system is $63 \%$ (Tables 4 and 6). In this study, there are four lasers in the SM-L-PBF mode and one in L-PBF. Although laser melting can be conducted more effectively with the multi-laser arrangement, the time consumed in the powder deposition step stays the same. The proportion of powder deposition time in the total build

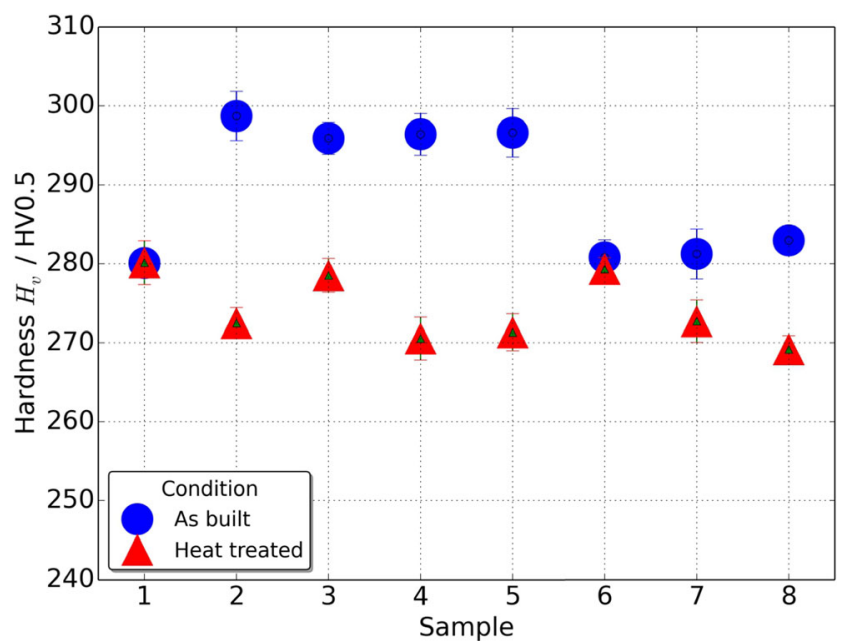

Fig. 14 Vickers hardness of the AB and HT specimens manufactured by SM-L-PBF 
Table 8 Results against ASTM standards on tensile requirements. Data rounded to 3 s.f

\begin{tabular}{llll}
\hline Specimen & UTS/MPa & $0.2 \%$ offset YS/MPa & Elongation/\% \\
\hline L-PBF HT cylinders & 841 & 523 & 68.5 \\
SM-L-PBF HT cylinders & 827 & 507 & 69.3 \\
ASTM requirements (B564, B446) & 827 & 414 & 30.0 \\
\hline
\end{tabular}

time in this study was particularly significant, as a thin powder layer of 30- $\mu \mathrm{m}$ thickness was used. As a result, the reduction in build time observed is less than the expected $75 \%$.

It should be noted that metal AM build rate is material and processing parameter dependent. For example, the RenAM500Q machine build rate reported in this study is $14 \mathrm{~cm}^{3} / \mathrm{h}$ when four $200 \mathrm{~W}$ lasers were used to process IN625 at a layer thickness of $30 \mu \mathrm{m}$ (Table 6). On another occasion, when processing AlSi10Mg with four $500 \mathrm{~W}$ lasers at a layer thickness of $60 \mu \mathrm{m}$, the build rate achieved was 77 $\mathrm{cm}^{3} / \mathrm{h}$ [22] (the RenAM 500Q is capable of achieving 150 $\mathrm{cm}^{3} / \mathrm{h}$ [23]). Moreover, this study does not aim to showcase the maximum material processing speed of the SM-L-PBF arrangement, but to demonstrate: (1) the fine control on mechanical properties through an optimised build parameter set, and (2) the increase in build rate of the SM-L-PBF arrangement when compared to that of the L-PBF.

\section{Conclusions}

IN625 specimens have been manufactured using a RenAM500Q machine with L-PBF and SM-L-PBF options. Stress-relieving heat treatment was carried out on half of the specimens. Optical density, microstructure, tensile behaviour and Vickers hardness of all laser configuration AB and HT specimens were evaluated. Results show that the SM-L-PBF system achieved a build rate of $14 \mathrm{~cm}^{3} / \mathrm{h}$ when processing IN625 at a powder layer thickness of $30 \mu \mathrm{m}$. The increase in build rate when compared to that of L-PBF is 2.74 times without compromising the mechanical behaviour and microstructure of the specimens. The stress-relieving heat treatment improves ductility of specimens across the board without compromising density or changing microstructure markedly. For all four L-PBF/SM-L-PBF and AB/HT datasets, average specimen density is above $99.99 \%$, which is on par with or exceed the value reported in literature [14]. Average tensile behaviour including UTS, $0.2 \%$ offset YS and elongation all exceeds ASTM requirements for IN625 specimens [19, 20]. Average specimen hardness and grain size are in the same order of that reported in literature (280HV0.5 [21], 10 to100 $\mu \mathrm{m}[16])$.

This study has addressed the research gaps by proposing an experimental design to benchmark the efficiency of a multilaser system, and demonstrating that the mechanical properties of specimens are not compromised when each specimen was manufactured by a single laser. Nevertheless, this may not be the case where multiple lasers are directed to melt individual specimen, thus more in-depth follow-up studies are required. This study has demonstrated that a multi-laser AM system opens up opportunities to tackle the impasse of low build rate in L-PBF in an industrial setting.

Funding information This work was supported by the EPSRC Centre for Innovative Manufacturing in Laser-based Production Processes (grant number EP/K030884/1).

Open Access This article is distributed under the terms of the Creative Commons Attribution 4.0 International License (http:// creativecommons.org/licenses/by/4.0/), which permits unrestricted use, distribution, and reproduction in any medium, provided you give appropriate credit to the original author(s) and the source, provide a link to the Creative Commons license, and indicate if changes were made.

\section{References}

1. Bhavar V, Kattire P, Patil VM, Khot SM, Gujar K, Singh RR (2017), Additive Manufacturing Handbook, Chapter 15: A review on powder bed fusion technology of metal additive manufacturing, Taylor \& Francis Group, https://doi.org/10.1201/978131511910615

2. Ford S, Despeisse M (2016) Additive manufacturing and sustainability: an exploratory study of the advantages and challenges. $\mathrm{J}$ Clean Prod 137:1573-1587. https://doi.org/10.1016/j.jclepro. 2016.04.150

3. Gokuldoss PK, Kolla S, Eckert J (2017) Additive manufacturing processes: selective laser melting, electron beam melting and binder jetting — selection guidelines. Materials 10:672. https://doi.org/10. 3390/ma10060672

4. Milewski JO (2017) Additive manufacturing of metals: from fundamental technology to rocket nozzles, medical implants, and custom jewelry, Springer, ISSN 2196-2812, pp. 90-98

5. Andani MT, Dehghani R, Karamooz-Ravari MR, Mirzaeifar R, Ni J (2017) Spatter formation in selective laser melting process using multi-laser technology. Elsevier Mater Des 131:460-469. https:// doi.org/10.1016/j.matdes.2017.06.040

6. Li F, Wang Z, Zeng X (2017) Microstructures and mechanical properties of Ti6Al4V alloy fabricated by multi-laser beam selective laser melting. Elsevier Mater Lett 199:79-83. https://doi.org/10. 1016/j.matlet.2017.04.050

7. Renishaw RenAM 500Q multi-laser AM system specification and data sheet https://www.renishaw.com/en/renam-500q\%2D\% 2D42781 
8. Renishaw In625-0402 powder for additive manufacturing https:// resources.renishaw.com/en/details/data-sheet-in625-0402-powderfor-additive-manufacturing\%2D\%2D 97039

9. Mercelis P, Kruth JP (2006) Residual stresses in selective laser sintering and selective laser melting. Rapid Prototyp J 12(5):254 265. https://doi.org/10.1108/13552540610707013

10. Losertová M, Kubeš V (2017) Microstructure and mechanical properties of selective laser melted Ti6A14V Alloy. IOP Conf Series: Materials Science and Engineering 266(2017):012009. https://doi. org/10.1088/1757-899X/266/1/012009

11. The Pennsylvania State University, Heat treatment procedure qualification, final technical report work performed under contract no. DE-FC07-99ID13841, Work Prepared for U.S. Department of Energy

12. ASTM E8/E8M Standard test methods for tension testing of metallic materials

13. ASTM E92-82 Standard test methods for Vickers hardness of metallic materials

14. Spierings AB, Bauer T, Dawson K, Collella A, Wegener K (2015) Processing ODS modified In625 using selective laser melting, Proceedings from the Solid Freeform Fabrication Symposium

15. Bauer T, Dawson K, Spierings AB, Wegener K (2015) Microstructure and mechanical characterisation of SLM processed Haynes $\circledR^{2} 30 \circledR$, Proceedings from the Solid Freeform Fabrication Symposium

16. Lia C, Whiteb R, Fangc XY, Weaverb M, Guoa YB (2017) Microstructure evolution characteristics of Inconel 625 alloy from selective laser melting to heat treatment. Mater Sci Eng A 705:20 31. https://doi.org/10.1016/j.msea.2017.08.058

17. Robinson J (2014) Optimisation of the selective laser melting process for the production of hybrid orthopaedic devices, $\mathrm{PhD}$ Thesis, The University of Liverpool, pp. 42-50, 113-161

18. Mukasyan A, Chapter 7 Dislocations and strengthening mechanisms, teaching materials, CBE 30361 Science of Engineering Materials, University of Notre Dame

19. ASTM B564 Standard specification for nickel alloy forgings

20. ASTM_B446 Standard specification for nickel-chromiummolybdenum-columbium alloy (UNS N06625), nickelchromium-molybdenum-silicon alloy (UNS N06219), and nickelchromium-molybdenum-tungsten alloy (UNS N06650) rod and bar

21. Harrison NJ (2016) Selective laser melting of nickel superalloys: solidification, microstructure and material response, $\mathrm{PhD}$ Thesis, The University of Sheffield, Faculty of Engineering, School of Mechanical Engineering, pp. 203

22. C. Martell (2018) The Renishaw additive manufacturing formula, Presentation Materials at the Renishaw Investor Day, http:// resources.renishaw.com/en/download/presentation-investor-day2018-additive-manufacturing\%2D\%2D102128

23. Renishaw RenAM 500 series additive manufacturing system data sheet, https://www.renishaw.com/en/renam-500q\%2D\%2D42781

Publisher's note Springer Nature remains neutral with regard to jurisdictional claims in published maps and institutional affiliations. 